\title{
Control Materials of Hydrogen Concentration in Micro Environment and Their Summary of Application
}

\author{
Min $\mathrm{Zhu}^{1}$, Cuihua $\mathrm{Lu}^{2}{ }^{*}$, and Hongqing Zhou ${ }^{2}$ \\ ${ }^{1}$ Naval Nniversity of Engineering, Wuhan, Hubei Province, China \\ ${ }^{2}$ Naval Aviation University, Yantai, Shandong Province, China
}

\begin{abstract}
Some materials will be hydrogenated to corrosion, such as metal materials, organic materials, polymer materials and so on, when the concentration of hydrogen in a mixed gas is greater than $4 \%$ in a closed space of micro environment. Their performances will be seriously affected. So removing or reducing the concentration of hydrogen in a micro environment can fundamentally solve the problem of hydrogenation corrosion. Metallic hydrogen removing agent and organic hydrogen removing agent are the main research directions of controlling materials of hydrogen concentration in micro environment. Current research status in the world are comprehensively reviewed from these two aspects. Features and application scopes of these two kinds of materials are pointed out separately, which provide a theoretical reference for the prevention of accidents caused by hydrogenation corrosion.
\end{abstract}

\section{Introduction}

If a complex atmosphere hydrogen removing material meets these 6 principles[1] proposed by R.L. Courtney. In the report, it can ensure the elimination of hydrogen without harmful side effects. Metallic hydrogen absorbing materials and organic hydrogen absorbing agent can meet these 6 principles.

The mechanism of metallic hydrogen absorbing material is that the surface of conventional metallic hydrogen-absorbing material whose hydrogen absorption properties meet requirements is covered with a layer of anti-poison material, which can be isolated from the poisonous gas and can avoid the impact on the hydrogen absorption properties of the internal material which is easy to be poisoned. (2):

The mechanism of organic hydrogen absorbing agent is as the formula (1) and formula

$$
\mathrm{R}^{\prime}-\mathrm{C} \equiv \mathrm{C}-\mathrm{R}+\mathrm{Cat} \rightarrow \mathrm{R}^{\prime}-\mathrm{C} \equiv \underset{\substack{\mid \\ \mathrm{Cat}^{*}}}{=\mathrm{C}-\mathrm{R}}
$$

\footnotetext{
*Corresponding author:1lu1978@163.com
} 


$$
\mathrm{R}^{\prime}-\mathrm{C} \equiv \mathrm{C}-\mathrm{R}+\mathrm{Cat} \rightarrow \mathrm{R}^{\prime}-\mathrm{C} \equiv \underset{\substack{\mid \\ \mathrm{Cat}^{*}}}{\mathrm{C}}-\mathrm{R}
$$

\section{Research status and development trend of metallic hydrogen- absorbing materials}

Metallic hydrogen-absorbing materials mainly include ionic hydrogen absorbing material, alloy hydrogen absorbing material, carbon and Nano hydrogen absorbing material, etc.

\section{1 lonic hydrogen absorbing material}

Ionic hydrogen absorbing material is an early hydrogen absorbing material. Study on synthesis and application of this kind of material has began in the 50's. Early applications are directly used as reducing agents.

Bogdanovic found that the hydrogen storage capacity of modified NaAlH4 with Ti can reach $3.1 \%-4.4 \%$ (mass fraction) and its cycle stability is also good.

Ionic hydride is generally used as a reducing agent and to supply a small amount of hydrogen, especially in underwater applications. Its unique advantages is whose gas product is only hydrogen, but ionic hydride is not optimistic on the prospects for large-scale applications.

\subsection{Alloy hydrogen absorbing material}

Alloy hydrogen absorbing material is a metal compound which can absorb, store and release hydrogen in large quantities under a certain temperature and hydrogen pressure. Alloy hydrogen absorbing material is the most widely used hydrogen absorbing material at present, because of its large hydrogen storage capacity, no pollution, safe and reliable, and relatively mature preparative technique. Alloy hydrogen absorbing material is mainly divided into magnesium series $\left(\mathrm{A}_{2} \mathrm{~B}\right.$ type $)$, rare earth series $\left(\mathrm{AB}_{5}\right.$ type), titanium series $(\mathrm{AB}$ type) and zirconium series $\left(\mathrm{AB}_{2}\right.$ type).

\subsubsection{Mg-based hydrogen absorbing materials}

Mg-based hydrogen absorbing materials are represented by $\mathrm{Mg}_{2} \mathrm{Ni}$. The American brooke haven national laboratory first smelted into $\mathrm{Mg}_{2} \mathrm{Ni}$ with magnesium and nickel in 1968 . Preliminary research on $\mathrm{Mg}-\mathrm{LiBH}_{4}$ system is carried out by Anderson et al[2], who explored a way to improve the hydrogen absorption properties of magnesium without activation. They found that $\mathrm{LiBH}_{4}$ could effectively improve the hydrogen absorbing kinetics of magnesium. Hydrogen absorbing mass fraction of $\mathrm{Mg}-\mathrm{LiBH}_{4}$ can reach $6.5 \%$ in $20 \mathrm{~min}$ at $300{ }^{\circ} \mathrm{C}$, which laid the foundation for the $\mathrm{Mg}$ based hydrogen absorbing material to be used as the hydrogen source of fuel-cell vehicles. Nano composite hydrogen absorbing materials have been made by Balooch etc. through high-energy ball-milling magnesium powder and crystalline or amorphous $\mathrm{ZrNiCr}$ and $\mathrm{ZrNi}_{1.6} \mathrm{Cr}_{0.4}$ powder. [3] Stone etc. [4] have made Mg-based hydrogen storage materials containing carbon nanotubes (Mg-3Ni-2 $\left.\mathrm{MnO}_{2}-0.25 \mathrm{CNTs}\right)$ by mechanical alloying and using $\mathrm{H}_{2}$ as a protective atmosphere, whose hydrogen storage mass fraction is $7.0 \%$. The hydrogen absorption process of the material will be completed in $100 \mathrm{~s}$, and its hydrogen desorption process will be completed in $600 \mathrm{~s}$ at $0.1 \mathrm{MPa}$ and the about $280^{\circ} \mathrm{C}$. Mroz[5] made Nano composite hydrogen absorbing material $\left(\mathrm{Mg}-3 \mathrm{Ni}-2 \mathrm{MnO}_{2}\right)$ by ball milling. It has a very good 
performance in circulating hydrogen storage, whose maximum hydrogen storage capacity is $6.5 \%$ and which can absorb $6.37 \%$ of $\mathrm{H}_{2}$ in $50 \mathrm{~s}$ and at $200^{\circ} \mathrm{C}$. After 60 cycles, the decrease in hydrogen storage is less than $0.1 \%$, but the time required for the absorption and desorption of hydrogen is increased with the increase of the number of cycles. Colmenares etc. [6] made $\mathrm{Mg}_{100-\mathrm{x}} \mathrm{Ni}_{\mathrm{x}}(\mathrm{x}=5,11.3,20,25)$ through the hydrogen burning-mechanical ball milling method. Alloy can be crushed and refined by ball milling process. Hydrogen desorption temperature of alloy which made through hydrogen burning-mechanical ball milling method is much lower than that of alloy which made through hydrogen burning method. The maximum hydrogen storage capacity of $\mathrm{Mg}_{80} \mathrm{Ni}_{20}$ is $2.77 \%$ in $600 \mathrm{~s}$ and at $313 \mathrm{~K}$. The maximum hydrogen storage capacity of $\mathrm{Mg}_{95} \mathrm{Ni}_{5}$ is $4.88 \%$ at $313 \mathrm{~K}$, and The maximum neon storage capacity is $5.41 \%$ at $473 \mathrm{~K}$. The hydrogen storage capacity of $\mathrm{Mg}-$ based hydrogen absorbing materials is big, but their kinetics performance and cycle life in alkaline solution are poor, then their properties need to be improved in these two areas.

\subsubsection{Rare earth series hydrogen absorbing materials}

Rare earth series hydrogen absorbing materials have $\mathrm{CaCu}_{5}$-type hexagonal structure. Their representative is $\mathrm{LaNi}_{5}$. Rare earth alloy has the advantages that its hydrogen absorbing rate is fast and it is easy to activate and so on, but it is not satisfactory in terms of performance and cost hydrogen storage, etc. Its performance can be improved by using the multi-alloy, which uses $\mathrm{Mm}$ (mixed rare earth), $\mathrm{Ca}$, $\mathrm{Ti}$ and other to replace parts of $\mathrm{La}$, and uses $\mathrm{Co}, \mathrm{Al}$, $\mathrm{Mn}, \mathrm{Sn}$ and other to replace parts of Ni. Powell's [7]research from the perspective of electronic shows that the performance of the alloy can greatly affect by using $\mathrm{Cu}$ and other 3D series metal or $\mathrm{Al}, \mathrm{Sn}$ and other $\mathrm{S}-\mathrm{P}$ series metal to replace $\mathrm{Ni}$ in $\mathrm{LaNi}_{5}$. Its hydrogen storage capacity can be increased, but the stability will be affected. Balooch[8] etc. prepared Nano $\mathrm{LaNi}_{4.2} \mathrm{Al}_{0.8}$ alloy through mechanical alloying method, whose hydrogen storage performance has been significantly improved. Research made by Yuan Xianxia et al. about $\mathrm{MINi}_{3.75} \mathrm{Co}_{0.65} \mathrm{Mn}_{0.4} \mathrm{Al}_{0.2}$ alloy shows that with the increase of temperature the hydrogen absorption and desorption rate of the hydrogen storage alloy is accelerated in the range of $253 \mathrm{~K}-358 \mathrm{~K}$. Hai Zhenwei[9] etc prepared $\mathrm{LaNi}_{5}$ series alloy powder, whose has the advantages of accurate chemical composition, high purity, small particle size and narrow distribution, etc. Compared with molten alloy it has better activation property, which shows that rare earth alloy has potential research value and application value.

\subsubsection{Titanium series hydrogen absorbing materials}

FeTi is the representative of titanium series hydrogen absorbing materials. Its advantage is that the hydrogen temperature is low and the price is moderate, but it is not easy to be activated, and easy to be poisoned by impurities such as $\mathrm{H}_{2} \mathrm{O}$ and $\mathrm{O}_{2}$, serious lag and unstable life. Now Ni and other metal parts are used to replace Fe to form ternary alloy in order to achieve room temperature activation. The results show that the activation properties of the alloy can be improved obviously by using $\mathrm{Mn}, \mathrm{Cr}, \mathrm{Zr}$ and $\mathrm{Ni}$ etc transition element to replace partial Fe of FeTi alloy. When the purity of $\mathrm{H}_{2}$ is more than $99.5 \%$, its cycle life is more than 26000 times. In addition, the activation property of FeTi alloy can be improved by mechanical milling and surface treatment with acid, alkali and other chemical reagents. At present, this kind of material has been widely used in Germany, the United States and other developed countries. Japan Metal Materials Technology Research Institute successfully developed the titanium- iron-oxide hydrogen storage system, which has the advantages of large amount of hydrogen absorption, fast hydrogenation, easy activation and so on. 


\subsubsection{Zirconium series hydrogen absorbing materials}

$\mathrm{ZrMn}_{2}$ is the representative of zirconium series hydrogen absorbing materials. Zr based alloys have a rich phase structure, such as C14, C15 and C36 Laves phase and a variety of B.C.C (solid solution). The mechanism and synergistic effect of each phase are currently being studied. The alloy has the advantages of high hydrogen absorption and desorption capacity, easy activation, small thermal effect (2-3 times smaller than LaNi5 and other materials) and so on. The properties of the multivariate $\mathrm{Zr}$ based hydrogen storage alloys are better which made by partial subtitution of $\mathrm{Zr}$ with $\mathrm{Ti}$ and partial subtitution of $\mathrm{V}, \mathrm{Cr}, \mathrm{Mn}$ with $\mathrm{Fe}, \mathrm{Co}, \mathrm{Ni}$.

\subsubsection{Composite hydrogen absorbing alloy materials}

In recent years, the research of composite hydrogen absorbing alloy materials has made a breakthrough. Nguyen[10] et al. found that the ball milled $\mathrm{Mg}_{2} \mathrm{Ni}-\mathrm{Ni}$ complex $(70 \% \mathrm{Ni})$ may be a non crystalline structure. Compared with $\mathrm{Mg}_{2} \mathrm{Ni}$, its hydrogen absorption rate is faster and its hydrogen absorption capacity is higher (up to 4\%), but the stability is poor. $\mathrm{Mg}_{1.0} \mathrm{Ni}_{1.0} \mathrm{~V}_{1.0}$ alloy prepared through ball milling by VSalazar[11] et al. Its hydrogen absorption capacity is $2.3 \%$, at $298 \mathrm{~K}$ and $3 \mathrm{MPa}$. The most prominent feature of this alloy is that it can store hydrogen at room temperature. Hydrogen storage capacity of $\mathrm{La}_{2} \mathrm{Mg}_{17}$ ${ }_{x} \mathrm{LaNi}_{5}$ complex developed by Carroll[12] et al. can be up to $5.3 \%$, but its activation temperature is high. Absorbing and disrobing hydrogen capacity of $\mathrm{Mg}-30 \% \mathrm{LaNi}_{5}$ complex can be up to $5 \%$ at $573 \mathrm{~K}$, which is made by Kaszuba[13] et al. through hightemperature sintering. Absorbing and disrobing hydrogen capacity of $\mathrm{Mg}-30 \% \mathrm{LaNi}_{5}$ and $\mathrm{MgH}_{2}-30 \% \mathrm{LaNi}_{5}$ can be up to $5 \%$ at $573 \mathrm{~K}$, and its dehydriding kinetics has been improved significantly, which are made by Holtz[14] et al. through ball-milling method. The hydrogen storage capacity of $\mathrm{Mg}-30 \% \mathrm{LaNi}_{2.28}$ complex is $5.4 \%$ at $553 \mathrm{~K}$ and $3 \mathrm{MPa}$, which is made by Rodrigo[15] et al. through mechanical alloyin. The hydrogen storage capacity of $\mathrm{La}_{1.5} \mathrm{Ni}_{0.5} \mathrm{Mg}_{17}$ can be up to $7.01 \%$ at $573 \mathrm{~K}$, which is made by Giorgi[16] et al. using the same method. Even at $373 \mathrm{~K}$ its hydrogen storage capacity can be up to $4.03 \%$ and the speed of hydrogen absorption and desorption is fast. Zhu et al. reported that the electrochemical properties and hydrogenation behavior of $\mathrm{Mg}_{2} \mathrm{Ni}_{\mathrm{MmNi}} \mathrm{Mm}_{5-\mathrm{x}}(\mathrm{CoAlMn})$ composites are better than single-phase alloy. Research made by Cotton[17] et al. shows that the hydrogen absorption capacity of $\mathrm{Mg}-30 \% \mathrm{TiMn}_{1.5}$ nanocomposites can be up to $4.4 \%$ at $523 \mathrm{~K} \sim 573 \mathrm{~K}$ and its saturated hydrogen storage capacity can also be up to $2.7 \%$ at $373 \mathrm{~K}$. Henrie et al.[18] reported that hydrogenation properties and hydrogen storage efficiency of new nanocomposites have been significantly improved which is made through adding organic solvent(tetrahydrofuran, cyclohexane etc. ) in magnesium and graphite by mechanical grinding.

\subsection{Carbon and nano hydrogen absorbing materials}

In recent years, due to the research upsurge of nano materials, carbon and nano-carbon materials for hydrogen storage have become a hot research topic. Carbon hydrogen absorbing materials mainly include high specific surface Activated carbon(AC), graphite nanofibers ( GNF), carbon nanofibers(CNF) and carbon nano-tube(CNT).

\subsubsection{High specific surface activated carbon}

Carpetis[19] first proposed that hydrogen can be stored in activated carbon by adsorption under the condition of low temperature. They first mentioned in their paper that low 
temperature adsorbent can be applied to the large hydrogen storage system, and pointed out that hydrogen's storage volume density in the active carbon is quite to liquid hydrogen's volume density. Zhou $\mathrm{Li}$ et al. used super activated carbon in hydrogen storage whose specific surface area is $3000 \mathrm{~m}^{2} / \mathrm{g}$ and micropore volume is $15 \mathrm{~mL} / \mathrm{g}$ (on the basis of $\mathrm{CO}_{2}$ adsorption). The hydrogen absorption capacity is $5 \%$ at $77 \mathrm{~K}$ and $3 \mathrm{Mpa}$, but with the increasing of temperature the hydrogen storage capacity is getting lower and lower. In addition, Zan Liang et al. pointed out that surface per unit mass activated carbon is larger, the greater amount of hydrogen can be adsorbed, which is certainly true especially in a high pressure. Lewis's[20] work focused on the study on mechanism of hydrogen absorption on activated carbon at the end of $1980 \mathrm{~s}$ and early 90 's.Best results obtained is that hydrogen adsorption capacity is $4.8 \%$ at $87 \mathrm{Kand} 59 \mathrm{~atm}$ through surface treatment of activated carbon. Heung et al.[21] studied that effect of gas impurities in hydrogen on the adsorption properties of activated carbon, pointed out that if super activated carbon was used as an adsorbent, hydrogen adsorption amount decreases no more than $30 \%$ which is caused by nitrogen impurities in hydrogen whose concentration is in the range of 500ppm. Tamm et al.[22] tested the hydrogen storage properties of a series of carbon sorbent at 300K, $190 \mathrm{~K}$ and $80 \mathrm{~K}$, such as activated carbon, activated carbon fiber, carbon black, carbon airgel, carbon molecular sieve. The results showed that only one test adsorbent's storage capacity can be increased in ten kinds of test adsorbents in about 200bar pressure and there was only a small amount of increment at $190 \mathrm{~K}$ and $300 \mathrm{~K}$, no increment in $80 \mathrm{~K}$. Overall, there is no report on activated carbon adsorbent at room temperature has better hydrogen storage properties.

\subsubsection{Graphite nanofibers}

Statement made by Devillers et al.[23] that graphite nanofibers have high hydrogen adsorption storage capacity sparked people's interest in this material. These materials are a mixture of ethylene, hydrogen and carbon monoxide. Through Choosing different catalyst, 3 different structures of graphite nanofiber scan be formed: tubular, flat-plate, fishbone shaped. The hydrogen storage capacity of three structures of graphite nanofiber are respectively $11 \mathrm{wt} \%, 53 \mathrm{wt} \%$ and $67 \mathrm{wt} \%$ at room temperature and at $11.35 \mathrm{Mpa}$, which were measured by Woyke et al.[24] But the conclusion was too high which the hydrogen adsorption capacity of fishbone shaped graphite nanofiber was $67 \%$, and then it was denied by other research groups. The validation results showed that the maximum amount of hydrogen storage at room temperature of graphite nanofiber is only between $0.08 \%-1.5 \%$. Therefore, Penzhorn et al.[25] believed that high density hydrogen storage of graphite nanofibers is no hope.

\subsubsection{Carbon nanofibers}

Carbon nanofibers(CNF) is the carbon fiber that its structure is solid and its fiber diameter is less than $1000 \mathrm{~nm}$. Vapor-grown carbon nanofibers whose diameter is about $80 \mathrm{~nm}$ made by Bonizzoni et al. [26] through floating catalyst method. Its hydrogen absorption capacity can be up to $12 \mathrm{wt} \%$ at room temperature and $11 \mathrm{Mpa}$ without treatment. Hydrogen absorption capacity of carbon nanofibers whose diameter is between $90 \mathrm{~nm}-125 \mathrm{~nm}$ can be up to about $10 \mathrm{wt} \%$ after ethanol dispersion and hydrochloric acid. Doni et al. [27] reported that the highest hydrogen storage capacity of carbon nanofibers is $10 \mathrm{wt} \%$ after making carbon nanofiber to open and removing impurity gas adsorbed on the surface of the fiber. Perevezentsev et al. [28] have measured that carbon nanofibers can store about $10 \mathrm{wt} \%$ hydrogen too. Srivatava et al. [29] found that carbon nanofibers daubed with lithium and potassium could adsorb $14 \mathrm{wt} \%$ aydrogen at $473 \mathrm{~K}$ and $20 \mathrm{wt} \%$ at $673 \mathrm{~K}$ under environmental 
pressure, but later they guessed the adsorption capacity measured might contain water vapor. Chambers et al.[30] developed carbon nanofibers whose average diameter was about $100 \mathrm{~nm}$. Its hydrogen adsorption capacity is about $10 \mathrm{wt} \%$ at $8-11 \mathrm{Mpa}$ and room temperature. These results still have not been proved by other people theoretically or experimentally. The computer simulation of nanofiber hydrogen adsorption can not explain these phenomena. The current computer simulation focuses on physical adsorption of hydrogen storage, and Diederich[31] proved even if the chemical adsorption exists, it is impossible to achieve the adsorption amount.

\subsubsection{Carbon nanotubes}

Since the discovery of carbon nanotubes in the accident in 1991 by Iijima, it quickly became a hot research topic in many high-tech fields due to its unique one-dimensional tubal structure and peculiar mechanical, electronic, properties etc. Carbon nanotubes can be divided into single-walled carbon nanotube (SWNT)and multi-walled carbon nanotube( MWNT). Sane et al. [32] first studied hydrogen adsorption performance of single-walled carbon nanotube without purification whose mass fraction is only $0.1-0.2$ $\mathrm{wt} \%$ by using TPD method. Estimated from the relevant results, the pure SWNT can absorb hydrogen at about $5-10 \mathrm{wt} \%$ at room temperature and $40 \mathrm{kPa}$, which is ten times the amount of activated carbon hydrogen storage and its adsorption heat is $19.6 \mathrm{~kJ} \cdot \mathrm{mol}^{-1}$. Ichimura et al.[33] have carried on the analysis to the interaction of hydrogen which is in SWNT. In their experiments, analyzable spectrum was tested through the thermal desorption spectrum and the main reversible desorption is in the range of $77 \mathrm{~K}-320 \mathrm{~K}$. At about $90 \mathrm{~K}$, the peak value of the activation energy was assumed to be the first sequence of desorption, which corresponded to the physical surface adsorption of single-walled carbon nanotubes. Janberg et al. [34] purified single-walled carbon nanotubes and studied the connection between the hydrogen storage of the single-walled carbon nanotube and its surface area. They found that the hydrogen storage capacity of SWNT is $8 \mathrm{wt} \%$, which was far more than traditional hydrogen storage system, but the hydrogen storage capacity of MWNT is less capable.

\section{Research status and development trend of organic hydrogen absorbing agent}

America's Sandia National Laboratories has used phenol, potassium hydroxide, chloro propyne etc. to form acetylenic compounds: phenyl propargyl ether(PPE) and dimerization of phenyl propargyl ether(DPPE) in the early 70's. Meanwhile the researchers used palladium black, calcium carbonate, asbestos or the 5\% palladium on alumina and PPE or DPPE for the preparation of hydrogen absorbing agent. Their research work proved that unsaturated organic compounds containing one or more of triple bonds had a superior absorption capacity in a closed system. Heterogeneous catalysis has be also proved that it was a good way to activate the hydrogenation reaction. The application scope of early organic hydrogen absorbing agent is limited because of their low melting point, such as DPB(1,4-diphenyl butadiyne)and DPPE. C A Colmenares has tested the equilibrium vapor pressures of DPB and DPPE. In the range of $23 \sim 75^{\circ} \mathrm{C}$, the vapor pressure of DPB vary in the range of $6.6 \times 10^{-7} \sim 6.0 \times 10^{-4}$ Torr and that of DPPE vary in the range of $3.5 \times 10^{-7} \sim$ $8.4 \times 10^{-7}$ Torr. G L Powell studied hydrogenation kinetics of DPB. The initial rate of DPB hydrogenation is slow and rate increases with the deepening of the reaction degree. Before reaching the theoretical maximum degree of reaction it keeps the reaction rate higher than the initial rate. The higher reaction rate of DPB in the high degree of reaction may be caused by eutectic which made by reactant mixture. 
In the 1990s, Sheppod et al. tested many potential hydrogen compounds, and found DEB(1,4-bis(phenylethynyl)benzene) had the best performance.

DEB's chemical structure is shown as the formula (3):<smiles>C(C#Cc1ccc(C#Cc2ccccc2)cc1)#Cc1ccccc1</smiles>

DEB is non-toxic, non-mutated crystalline solid. The melting point of DEB is $179{ }^{\circ} \mathrm{C}$ and all products of hydrogenation melt at $87^{\circ} \mathrm{C}$. The standard component of DEB hydrogen absorbing agent is a mixture of $75 \%$ DEB and $25 \%$ carbon catalyst (with $5 \%$ Pd on carbon). At 70 degrees and under the environment of $\mathrm{N}_{2}$, the hydrogen absorbing agent can be stable for 18 months without the presence of hydrogen. Because DEB contains two triple bonds, $1 \mathrm{~mol}$ DEB can react with $4 \mathrm{~mol}$ hydrogen. DEB and hydrogen reaction is fast, exothermic, irreversible. Hydrogen storage capacity per gram DEB is in $240 \sim 330 \mathrm{~cm}^{3}$. The reaction is close to the stoichiometric, and reachs $>90 \%$ of the theoretical level. If hydrogen is injected at the rate of $10^{-3} \mathrm{~cm}^{3} / \mathrm{sec}$ in nitrogen environment, the hydrogen concentration can be kept under 5ppm until the reaction degree of DEB reachs $>90 \%$ of the theoretical level. The reaction rate of $\mathrm{DEB}$ and hydrogen is faster with the increase of the temperature. The study also found that $\mathrm{CO}$ and several chlorinated volatile organic compounds inhibited the reaction of DEB and hydrogen. $\mathrm{M}$. Balooch et al. was also measured pure DEB, the mixture of $\mathrm{DEB}$ and carbon supported palladium (DEB-Pd/C), vapor pressure of hydrogenated $\mathrm{DEB}-\mathrm{Pd} / \mathrm{C}$ from room temperature to the melting point $\left(179^{\circ} \mathrm{C}\right)$. The results showed that vapor pressure of hydrogenated $\mathrm{DEB}-\mathrm{Pd} / \mathrm{C}$ was the highest. $\mathrm{DEB}-\mathrm{Pd} / \mathrm{C}$ 's vapor pressure was higher than the predictive value through the ideal solution model, which showed that there were positive interaction when DEB and carbon supported palladium form $\mathrm{DEB}-\mathrm{Pd} / \mathrm{C}$.

\section{Conclusion}

Metallic hydrogen removing agent and organic hydrogen removing agent are the main research directions of controlling materials of hydrogen concentration in micro environment. Current research status in the world are comprehensively reviewed from these two aspects.Metallic hydrogen absorbing materials mainly include ionic hydrogen absorbing material, alloy hydrogen absorbing material, carbon and nano hydrogen absorbing material, etc.Alloy hydrogen absorbing material is the most widely used hydrogen absorbing material at present, because of its large hydrogen storage capacity, no pollution, safe and reliable, and relatively mature preparative technique.In recent years, carbon and nano-carbon material for hydrogen storage is a hot research topic. Research found that the hydrogen storage capacity of SWNT is far more than traditional hydrogen storage system. The application scope of early organic hydrogen absorbing agent is limited because of their low melting-point, such as DPB and DPPE. The study found that DEB' melting-point was $179^{\circ} \mathrm{C}$ and its hydrogen storage capacity was good.

\section{References}

1. R. L. Courtney, L. A. Harrah, Organic Hydrogen Getters Part I: Introductory Report, SLA(1974)

2. R. D. Anderson, R. L. Courtney, L. A. Harrah, Low temperature, low pressure hydrogen gettering. U.S. Patent 3896042

3. R. M. Balooch, W. E. Wang, J. D. LeMay, Thermochemical properties of the hydrogen getter DEB, Journal of Nuclear Materials, 270, 248-252 (1999) 
4. M. Stone, M. Benson, C. Orme, et al. Improved Hydrogen Gas Getters for TRU Waste, INEEL/EXT-02-00564, (2002)

5. G. Mroz, Test plan for hydrogen getters project-phase II, LA-UR-99-1219, (1999)

6. C. A. Colmenares, R. G. Garza, Equilibrium vapor pressures of the hydrogen getters $D P B$ and DPPE. UCRL-85972, (1981)

7. G. L. Powell, Hydriding kinetics of an organic hydrogen getter-DPB, Journal of Alloys and Compounds, 446-447: 402-404(2007)

8. M. Balooch, W. E. Wang, J. R. Kirkpatrick, Hydrogen uptake mechanism of a siliconerubber DEB getter mixture, Journal of Polymer Science: Part B: Polymer Physics, 39, 425-431 (2001)

9. Hai Zhenwei, Tang Jiansheng, Gao Zhenheng, Studies on 1,4-Bis (Phenyl Ethynyl) Benzene and Its Bis Substituted Phenyl Derivatives, chemical journal of Chinese universities, 11(6): 586-590 (1990)

10. P. Nguyen, Synthesis of symmetric 1,4-bis(p-R-phenylethynyl)benzenes via palladium/copper catalyzed cross coupling and comments on the coupling and comments on the coupling of aryl halides with terminal alkynes, Inorganica Chimica Acta, 220, 289-296(1994)

11. K. VSalazar, D. W. Carroll, M. Trkula, et al. Hydrogen uptake on film surfaces produced by a unique codeposition process, Applied Surface Science , 214, 20-26(2003)

12. D. W. Carroll, D. R. Pesiri, K. VSalazar, et al. Codeposition of the DEB-Palladium hydrogen getter system, LA-UR-00-3067, (2000)

13. J. P. Kaszuba, E. Peterson,E. Mroz, et al. Development of Hydrogen Gas Getters for TRU Waste, WM-4237, WM'04 Conference, (2004)

14. R. L. Holtz, V. Provenzano, M. A. Imam. Overview of Nanophase Metals and Alloys for Gas Sensors, Getters, and Hydrogen Storage, Nanostructured Materials, 7, 259264(1996)

15. L. Rodrigo, J. A. Sawicki, R. E. Johnson, Characterization of Deactivated Metal Getters Used in a Glove Box Purification System, Fusion Science \& Technology, 28, 1410-1415(1995)

16. T. A. Giorgi, B. Ferrario, B. Storey, An Updated Review of Getters and Bettering, J. Vat. Sci. Technol., 3, 417-423(1985)

17. F. A. Cotton, G. Wilkinson, Transition-Metal Hydrides, Advanced Inorganic Chemistry, 3rd Edition, Interscience Publishers, New York, 186-187(1972)

18. J. O. Henrie, D. J. Flesher, G. J. Quinn, et al. Hydrogen Control in the Handling, Shipping, and Storage of Wet Radioactive Waste, GEND-052, U.S. Department of Energy, (1986)

19. C. Carpetis. Hydrogen-Ttitium Getters and Their Applications, KCP-613-4410, AlliedSignal Aerospace Co., (1990)

20. F. A. Lewis, The Palladium-Hydrogen System, Academic Press, (1967)

21. L. K. Heung, Tritium Transport Vessel Using Depleted Uranium, Fusion Tech., 28, 1385-1390(1995)

22. U. Tamm, E. Hutter, G. Neffe, et al. Uranium Getters for Tritium Cleanup at the Tritium Laboratory Karlsruhe (TLK), Fusion Tech., 21, 983-987(1992)

23. M. Devillers, M. Sirch, S. Bredendiek-Kamper, et al. Characterization of the ZrCoHydrogen System in View of Its Use for Tritium Storage, Chem. Mater., 2, 255 262(1990) 
24. T. Woyke, C. Schiller, U. Schmidt, et al. $\mathrm{ZrCo}$ as a $\mathrm{New} \mathrm{H}_{2}$ Storage and Getter for Lyman- $\alpha$ Radiation Sources, Appl. Optics, 34, 155-158(1995)

25. R. D. Penzhorn, M. Devillers, M. Sirch, Evaluation of ZrCo and Other Getters for Tritium Handling and Storage, J Nucl. Mater., 170, 217-231(1990)

26. G. Bonizzoni, A. Conte, G. Gatto, et al. Tritium Storage Plant Based on a Combination of St707 and St737 Getter Alloy Beds for High Field Fusion Machines, Vacuum, 41, 1500-1502(1990)

27. F. Doni, C. Boffito, F. Farrario, Hydrogen Isotope Sorption and Recovery by a Nonevaporable Getter Combined with a Chemical Compressor Material, J Vat. Sci. Tech., 4, 2447-2451(1986)

28. A. N. Perevezentsev, A. C. Bell, R. Lalsser, et al. Safety Aspects of Tritium Storage in Metal Hydride Form, Fusion Technology, 28, 1404-1409(1995)

29. S. Srivatava, O. N. Srivastava, Synthesis, Characterization and Hydrogenation Behavior of Composite Hydrogen Storage Alloys, LaNi5/La2Ni7, LaNi3, Journal of Alloys \& Compounds, 281, 197-205(1999)

30. A. Chambers, C. Park, R. T. K. Baker, et al. Hydrogen Storage in Graphite Nanofibers[J], J. Phys. Chem. B, 102, 4253-4257(1998)

31. F. Diederich, F. L. Whetten, C60: From Soot to Superconductor, Angew. Chem. Int. Ed., 30, 678-683(1991)

32. M. Sane, H. Nishimura, K. Ichimura, Dissociation of Hydrogen Molecules by a FirstStage Graphite-Caesiurn Intercalation Compound, Synthetic Metals, 31, 73-78(1989)

33. K. Ichimura, M. Sano, Gettering of Hydrogen and Oxygen by Alkali-Metal Graphite Intercalation Compounds, Journal of Vacuum Science \& Technology A Vacuum Surfaces \& Films, 10, 543-546(1992)

34. K. Janberg, F. Petrucci. Dry Storage in Casks at the Site of Super-Phenex- The Special Problem of the Tritium Getter-Process Within a Transport and Storage Cask Filled With Absorber Rods[J], in the Proceedings of ICEM'95, 1, 285-287(1995) 